\title{
Population Dynamics in Southern Europe: A Local-Scale Analysis, 1961-2011
}

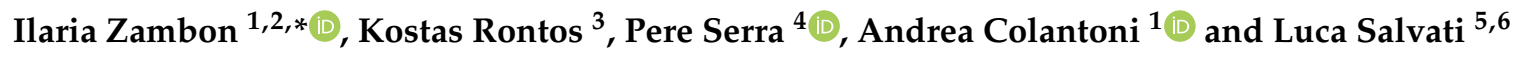 \\ 1 Department of Agricultural and Forestry Sciences (DAFNE), Tuscia University, Via San Camillo de Lellis, 5, \\ I-01100 Viterbo, Italy; colantoni@unitus.it \\ 2 Soil Erosion and Degradation Research Group, Department of Geography, University of Valencia, \\ ES-46010 Valencia, Spain \\ 3 Department of Sociology, University of the Aegean, Mytilene GR-81100, Greece; k.rontos@soc.aegean.gr \\ 4 Grumets Research Group, Department of Geography, Autonomous University of Barcelona, \\ ES-08193 Barcelona, Spain; pere.serra@uab.cat \\ 5 Council for Agricultural Research and Economics (CREA), I-52100 Arezzo, Italy; luca.salvati@crea.gov.it \\ 6 Global Change Research Institute of the Czech Academy of Sciences, CZ-37005 České Budějovice, \\ Czech Republic \\ * Correspondence: ilaria.zambon@unitus.it
}

Received: 7 December 2018; Accepted: 20 December 2018; Published: 25 December 2018

\begin{abstract}
Different socioeconomic, historical, political, and cultural factors have influenced long-term settlement patterns and demographic structures in Europe. Southern Europe is considered a relatively homogeneous region as far as settlement characteristics and population dynamics are concerned. Within-country local variability in the spatial distribution of population is high, and inherent differences across countries may outline distinct demographic patterns at regional scale. A comparative, local-scale analysis of population distribution in five countries (Spain, Italy, Croatia, Greece, and Cyprus) over a relatively long time period (1961-2011) contributes to identify latent demographic trends in Mediterranean Europe at the spatial scale of Local Administrative Units (LAU). A spatially-explicit analysis of basic indicators of population density and demographic change allows identification of territorial disparities, reflecting local-scale settlement patterns common to different countries (e.g., population growth along coastal districts). These patterns consolidate a metropolitan hierarchy centered on large-mainly compact—cities and more dispersed conurbations along coastal areas. At the same time, the examined countries present different territorial contexts resulting in distinct population dynamics in turn influenced by internal (e.g., national policies, culture and local identity, class segregation) and exogenous (e.g., economic cycle, urbanization models) factors. A spatially-explicit analysis of demographic trends at local scale may contribute to rethinking urban strategies and adapting spatial planning to heterogeneous socioeconomic contexts across Europe.
\end{abstract}

Keywords: territorial disparities; demographic trends; regional development; Southern Europe; Indicators

\section{Introduction}

Local development and territorial disparities represent key issues in regional science [1]. While highly informative of current patterns and trends in local development, a comparative analysis of relevant socioeconomic and demographic attributes over a relatively long-time interval and detailed spatial scale is actually lacking for Europe [2-6]. This kind of analysis is particularly interesting in an economically-advanced region such as Europe, since individual countries exhibit distinctive characteristics deriving from their intrinsic socioeconomic structure, history, and political/cultural background [7-14]. In these regards, multiple factors have been demonstrated to drive metropolitan 
concentration in Europe, including (i) globalization of economic activities, (ii) accelerated structural changes toward advanced services, and (iii) a more intense cycle of building activity [15]. Analysis of relevant indicators of demographic dynamics at a disaggregated spatial scale may outline recent suburbanization trends. These trends reflect increased mobility of affluent population segments toward peri-urban areas, underlining new residential preferences for large dwellings in green spaces, thanks to increased car ownership $[16,17]$. A spatial analysis of demographic indicators may also reveal new patterns of social segregation and regional disparities [18-22]. Based on these circumstances, regional changes in economic restructuring, demographic systems and urban sprawl patterns can have relevant consequences in terms of community marginalization, poverty, socio-spatial, and political imbalances [23-25].

Local-scale population dynamics is probably one of the most pertinent variables whose investigation may advance knowledge on the recent evolution of European regions, revealing complex territorial and social transformations $[6,26,27]$ that lead to different models of urban growth [1,28-30]. While urbanization-the concentration of population and economic activities in cities and towns-resulted from the uneven industrial development of the 18th century and the expansion of international commerce in the 19th and 20th centuries [31], population concentration in central cities was mostly dependent on internal migration during the last century. Rural-urban migration was shaped by multiple factors, including (i) the increased productivity of the agricultural sector thanks to new technologies, (ii) the development of transport infrastructure, and (iii) radical improvements in urban sanitation and sewage systems. In this context, compact urbanization was typically associated with concentration of settlements and a medium-high degree of population density. Dispersed urbanization in more recent times was identified as a dominant urbanization mode, stimulating residential mobility to suburban areas. Suburbanization determined an overall decline of population in central cities [14,32,33], with relevant implications for both metropolitan structures and socioeconomic functions $[6,34]$.

However, these patterns were (and still are) relatively different across Europe. Demographic processes, residential mobility across metropolitan regions, and the consequent urban patterns in most British, French, or German cities diverged strongly from the highly regulated and compact urbanization observed in Eastern Europe and from semi-dense, spatially-volatile, and mostly unregulated dynamics typical of Southern Europe [3,35]. Given the inherent complexity of urban landscapes [5,6], spatial heterogeneity in local-scale population dynamics has been little explored across European countries and/or macro-regions [3]. For instance, compared to Western and Northern Europe, Mediterranean regions have experienced a more recent and intense suburbanization, accelerated by rapid demographic changes [36]. More recently, urban cycles in Southern Europe have been re-contextualized to a new socioeconomic context shaped by economic downturns, including the expansion of the early 2000s and the subsequent recession of the late 2000s.

A comprehensive analysis of population dynamics in Southern European metropolitan regions can benefit from the definition of Large Urban Zones (LUZs) originally proposed and operationalized by Eurostat, the Statistical Office of the European Commission [3]. Considering LUZs as the elementary analysis' unit, a vast amount of data and indicators is available for the last two-three decades, allowing a proper comparison among metropolitan regions as far as basic demographic and economic indicators are concerned. By contrast, databases including representative variables at a more detailed spatial scales (e.g., municipal level) are relatively scarce. Considering a relatively long time period (between 1961 and 2011), the present work provides a comparative analysis of local-scale population dynamics derived from national censuses carried out in five countries of Mediterranean Europe, adopting municipalities as the elementary analysis' unit. Using spatial mapping and descriptive statistics, long-term population divides can be studied along urban-rural and coastal-inland gradients [18,37], filling a gap in the current literature on regional disparities in Europe. In this regard, integration of basic indicators, e.g., demographic change and fluctuations in population density, improves a basic knowledge of both intensity and spatial direction of regional disparities, reflecting trans-scalar dynamics over 
time [38]. Under the hypothesis that the examined countries present distinct socioeconomic contexts resulting in heterogeneous population dynamics, the present work contributes to highlight both internal (e.g., national policies, culture, and local identity) and external (e.g., economic cycle, urbanization models) factors shaping local-scale population dynamics and urban hierarchy [28,39-41]. In this perspective, we assume that urbanization processes tend to vary from country to country, being influenced by place-specific forces that can be better characterized in a comparative analysis of long-term demographic trends [42-44]. Moreover, we verify the assumption that local-scale demographic growth is positively correlated with population density, demonstrating that population dynamics may consolidate socioeconomic divides among regions and districts. Stability over time of the positive relationship between population density and demographic growth rate was finally tested with the aim to identify distinctive urban cycles in the examined countries. A spatially-explicit analysis of population trends at local scale may definitely contribute to reframe urban strategies and regional policies adapting to heterogeneous and rapidly-changing socioeconomic contexts across Mediterranean Europe [14,19,34,45].

\section{Methodology}

Meeting the demand for local statistics, Eurostat has adopted a NUTS-compatible system of local administrative units (LAU). LAUs are the constituent elements of NUTS, as they include municipalities and/or 'communes' (being representative of local communities), trying to homogenize multiple country-based definitions of local governance levels. Until 2016, local units were based on two existing administrative scales: (i) LAU level 1 (formerly NUTS level 4), defined for most countries as homogeneous local districts of economic or administrative interest; and (ii) the lower LAU level 2 (formerly NUTS level 5), defined as municipalities or equivalent units in the 28 EU Member States. LAUs have an important role in official statistics, considering both (i) data availability and (ii) relevance for implementation of policies addressing local-scale matters at a more detailed spatial scale than administrative regions (NUTS-2) or prefectures/provinces (NUTS-3). As LAUs are subject to some changes over time, Eurostat updates a list of spatial units and boundaries.

The present study makes use of a collection of population data collected every 10 years based on European Local Administrative Units (LUAs) for the period 1961-2011. Five Mediterranean countries with different areal and population size were considered here (Spain, Italy, Croatia, Greece, and Cyprus) being representative of population dynamics in northern Mediterranean basin. The level of territorial detail for most countries corresponds to LUA level 2; for Greece, LUA level 1 coverage was considered here. Data were recalculated for the most recent administrative boundaries (2011) and interpolated for the 1961-2011 census period, every 10 years. Although the spatial units are statistically homogeneous across countries, a source of heterogeneity exists when considering the average size of municipalities in Southern Europe [46-51]. However, the exploratory aim of this study justifies the use of municipalities as elementary analysis' units and takes account of spatial heterogeneity due to different size of local governance units.

Municipal-scale population data were processed, analyzed, and represented using ESRI ArcMap software (ESRI, Redwoods, USA). Two indicators were adopted in this study: (i) population density, calculated as the ratio of resident population in municipal area (hectares); and (ii) percent annual change in resident population (1961-1971, 1971-1981, 1981-1991, 1991-2001, and 2001-2011). In addition to density maps, a scatter plot was used to compare countries according to the spatial variability of the adopted indicators. Under the assumption that spatial variation in population growth rates is dependent on local background contexts, the relationship between demographic growth over time and population density (intended as a proxy of concentration and agglomeration processes along urban-rural and coastal-inland gradients) was tested in this study using a pair-wise correlation analysis based on both parametric (Pearson product-moment) coefficients and non-parametric (Spearman rank and Kendall cograduation) coefficients. Positive and negative coefficients indicate that population expanded in conditions respectively of higher density (e.g., in urban areas) and lower density 
(e.g., in rural areas). Significant pair-wise correlations were tested at $p<0.05$ after Bonferroni's correction for multiple comparisons. Integration of parametric and non-parametric correlation analysis allows identification of both linear and non-linear relationships between population density and demographic growth.

\section{Results}

Urban population in the Mediterranean basin has grown from 89 million in 1950 to 258 million inhabitants in 1995 while it is estimated to reach 416 million inhabitants in 2030. Most of the Mediterranean urban population lives in European countries like Italy and Spain (Table 1). In 1995, European countries displayed urbanization levels ranging from $59.2 \%$ (Greece) to $76.5 \%$ (Spain). By the year 2030, all Mediterranean countries will be even more deeply urbanized [52-54]. Mediterranean countries display heterogeneous population dynamics at LAU scale. In all countries, the densest locations coincided with central cities and the associated metropolitan areas, including capital cities (such as Madrid, Rome, and Athens) and regional urban centers of high economic relevance, such as Valencia, Barcelona, Marseille, Milan, Naples, and Istanbul were clearly highlighted (Figure 1).

Table 1. Basic statistics for the investigated countries in Southern Europe

\begin{tabular}{ccccc}
\hline Country & No Municipalities & Area $\left.\mathbf{( k m}^{\mathbf{2}}\right)$ & Population (2011) & Density (Population/ $\mathbf{k m}^{\mathbf{2}}$ ) \\
\hline Spain & 8116 & 521,841 & $46,816,010$ & 90 \\
Italy & 8092 & 301,365 & $59,434,413$ & 197 \\
Croatia & 556 & 57,048 & $4,284,889$ & 75 \\
Greece & 1034 & 132,033 & $10,939,727$ & 83 \\
Cyprus & 615 & 10,419 & $1,125,000$ & 108 \\
\hline
\end{tabular}

Population density allows identification of specific urban-rural and coastal-inland gradients for each country. A comparative analysis of population density for 1961 and 2011 indicates that central cities have progressively widened their boundaries and influence zones, with the corresponding increase of population density in their peripheral crowns. Population dynamics in all countries emphasize distinctive processes of urbanization/suburbanization/re-urbanization occurring in Mediterranean Europe since World War II: (i) settlement (and population) sprawl around major urban centers; and (ii) coastalization, consolidating rural-urban divides in Southern Europe. Focusing on the main urban centers of the region, capital cities such as Madrid, Athens, and Rome revealed a strong increase in population density around their metropolitan areas. At the same time, medium-large cities have also undergone processes of settlement dispersion. Coastal areas exhibited a marked increase in population density, possibly thanks to tourism development. Population growth (per cent annual change between 1961 and 2011) evidenced general patterns of residential mobility in the last 50 years. Together with a slight decline of the largest urban nuclei, areas around central cities displayed the highest positive rate of growth. Medium-sized cities were also benefiting from these demographic trends. Conversely, population decline was systematically observed in internal, marginal, and economically-disadvantaged areas of almost all examined countries and particularly in Spain, Italy, and Greece. 

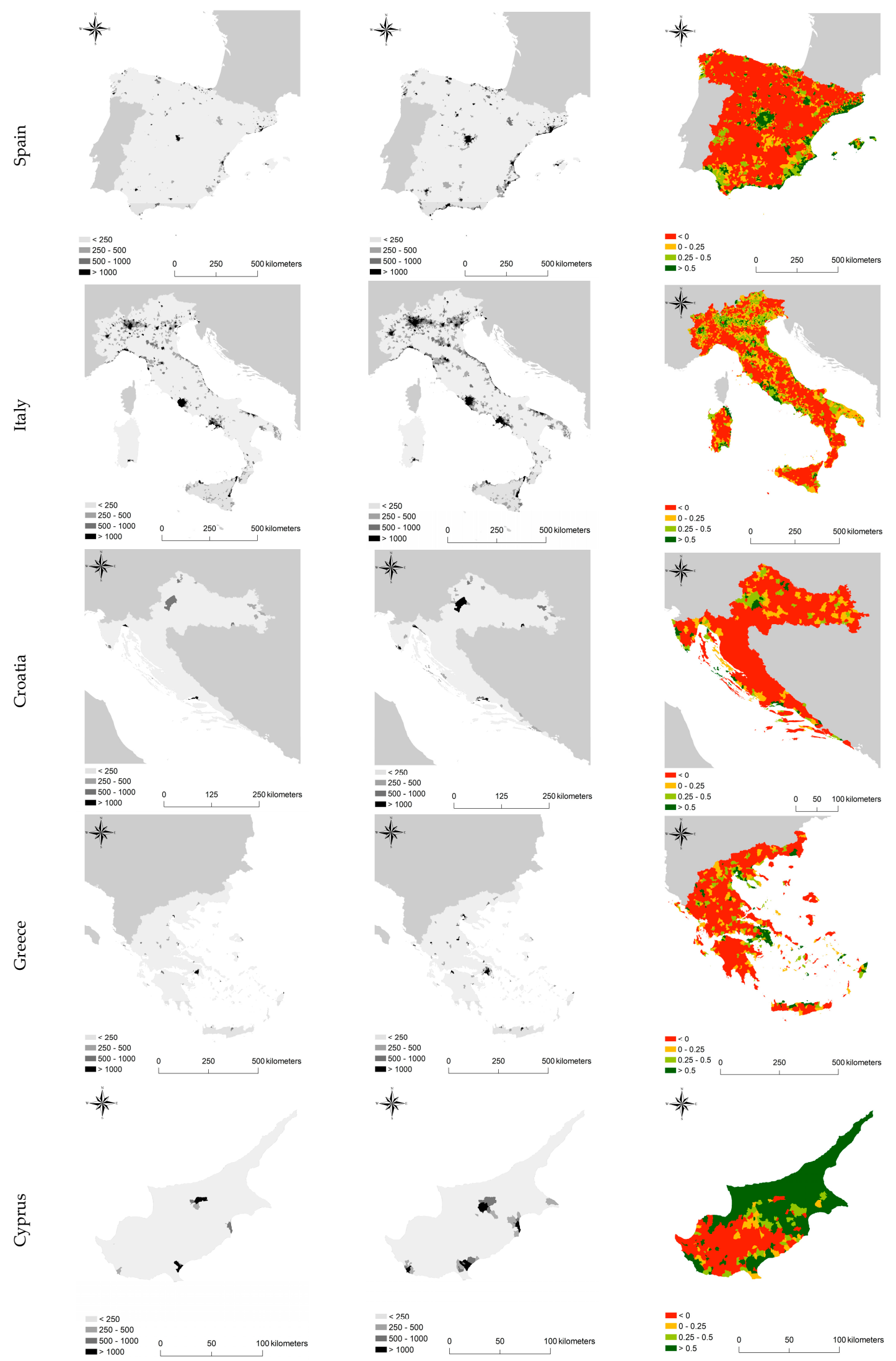

Figure 1. Population density (inhabitants/hectare) in 1961 (left), 2011 (middle) and per cent annual rate of population growth in 1961-2011 (right). 
Correlation analysis (Table 2) indicates a positive linkage between population density and demographic growth rate in the first two decades (1961-1971, 1971-1981) in Italy, Spain and, partly, Greece. A similar correlation was found in the last decade (2001-2011) for the same countries. Parametric and non-parametric coefficients were substantially similar, outlining a linear relationship between variables. Croatia had relatively high correlation coefficients in the first two decades of study, declining moderately in the third and fourth decades. Correlation coefficients were milder in the last decade. Contrary to the other Mediterranean countries, Cyprus displayed the highest correlation coefficient for 1981-1991.

Table 2. Parametric and non-parametric correlation coefficients between population density and annual demographic growth rate in Southern Europe by country and time interval (all coefficients are significant at $p<0.05$ after Bonferroni's correction for multiple comparisons)

\begin{tabular}{|c|c|c|c|c|c|}
\hline Country & 1961-1971 & 1971-1981 & 1981-1991 & 1991-2001 & 2001-2011 \\
\hline \multicolumn{6}{|c|}{ Pearson product moment coefficient } \\
\hline Spain & 0.471 & 0.487 & 0.207 & 0.147 & 0.313 \\
\hline Italy & 0.456 & 0.464 & 0.218 & 0.368 & 0.384 \\
\hline Greece & 0.484 & 0.248 & 0.104 & 0.063 & 0.367 \\
\hline Cyprus & 0.128 & 0.198 & 0.526 & 0.167 & 0.105 \\
\hline Croatia & 0.498 & 0.477 & 0.366 & 0.368 & 0.095 \\
\hline \multicolumn{6}{|c|}{ Spearman rank coefficient } \\
\hline Spain & 0.613 & 0.644 & 0.461 & 0.287 & 0.504 \\
\hline Italy & 0.553 & 0.553 & 0.457 & 0.463 & 0.474 \\
\hline Greece & 0.484 & 0.375 & 0.206 & 0.217 & 0.534 \\
\hline Cyprus & 0.125 & 0.229 & 0.496 & 0.370 & 0.198 \\
\hline Croatia & 0.473 & 0.489 & 0.456 & 0.383 & 0.304 \\
\hline \multicolumn{6}{|c|}{ Kendall cograduation coefficient } \\
\hline Spain & 0.443 & 0.469 & 0.327 & 0.202 & 0.35 \\
\hline Italy & 0.407 & 0.402 & 0.332 & 0.331 & 0.336 \\
\hline Greece & 0.341 & 0.262 & 0.143 & 0.151 & 0.377 \\
\hline Cyprus & 0.085 & 0.155 & 0.349 & 0.26 & 0.136 \\
\hline Croatia & 0.329 & 0.346 & 0.319 & 0.263 & 0.215 \\
\hline
\end{tabular}

Figure 2 illustrates a cluster analysis run on correlation coefficients by country and time period (see Table 2) illustrating similarity in the relationship between population density and demographic growth rate in Southern Europe. Both parametric and non-parametric correlation analysis outlined a strong similarity in population dynamics of Italy and Spain, outlining a similar urban cycle in both countries. Greece showed similarities with both Croatia and Italy-Spain, possibly indicating a more heterogeneous urban cycle. Croatia was placed in-between Western Mediterranean countries like Italy and Spain (homogeneous population dynamics) and Eastern Mediterranean countries such as Greece and, partly, Cyprus (more heterogeneous population dynamics). Likely because of limited country (and population) size, Cyprus demographic dynamics were rather divergent from the other four countries investigated in this study, possibly outlining a differential urban cycle. 


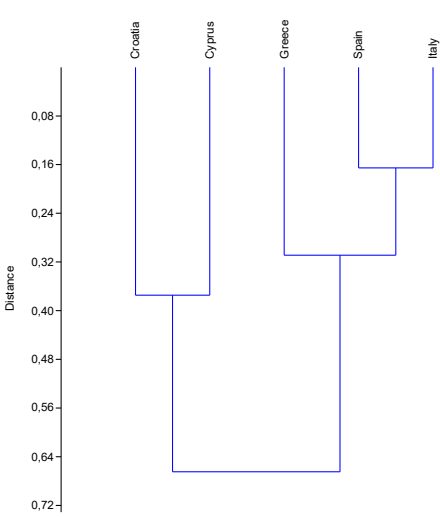

(a)

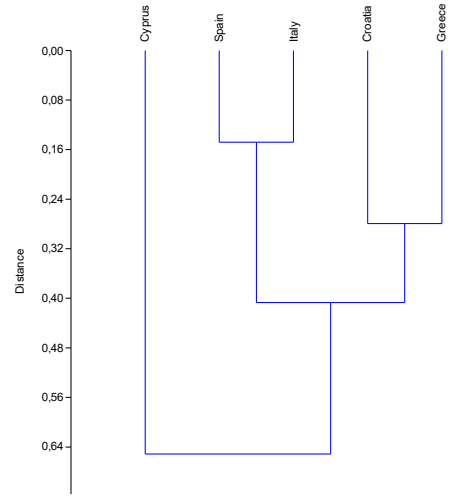

(b)

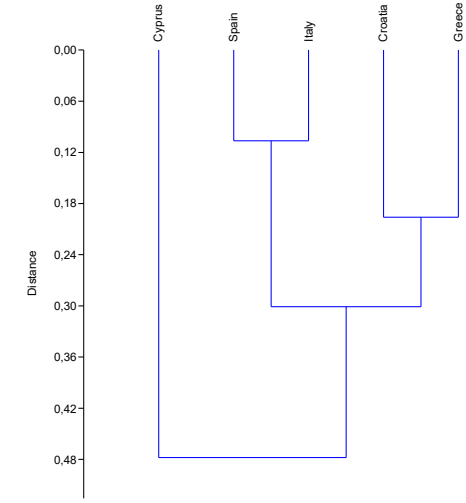

(c)

Figure 2. Hierarchical clustering (Euclidean distances, Ward's agglomeration rule) evidencing similarities and differences among countries in the relationship between population density and annual demographic growth rate. (a) Pearson coefficients; (b) Spearman coefficients; (c) Kendall coefficients).

\section{Discussion}

Since World War II, European urban areas have grown by $78 \%$, while their population has increased by only $33 \%$ [55-58]. Such changes have shaped the structure and functions of peri-urban landscapes around central cities [19,20,59-64]. Moreover, these transformations have frequently led to regional disparities and population divides, especially evident at the local scale [13]. In these regards, few studies have compared population dynamics in European countries at a detailed enough spatial scale, concentrating mostly on a metropolitan scale analysis based on LUZs and similar aggregated statistics [12]. The novelty of the present study lies in a diachronic analysis of long-term demographic trends (1961-2011) at the municipal scale in five countries of Southern Europe, evidencing similarities and differences in recent urban patterns.

The present study has identified a demographic profile for each Mediterranean country, expressing different development trends at local scale $[9,65,66]$. The exploratory analysis highlighted the intrinsic characteristics of the contexts analyzed using interpretative indicators diverging along urban-rural and coastal-inland gradients $[11,20,42,67]$. Under the assumption that population fluctuations reveal how people live and move around space, demographic changes are mostly linked to urbanization processes, being a key driver of land-use change and socioeconomic transformations $[4,14,30,68]$. The integration of basic indicators, e.g., demographic variation over time and population density, allows identification of more latent territorial disparities [7], outlining recent demographic trends and their impact on settlement structure and urbanization patterns.

Population deconcentration in urban cores, demographic expansion of peri-urban crowns, and depopulation and abandonment of more marginal rural districts contribute to consolidate population divides in high-density and low-density areas. Demographic growth taking place in Mediterranean Europe evidenced divergent local contexts, possibly leading to regional disparities [22,55]. Intense processes of urbanization were observed in the last decades, leading to uneven dispersion of population and economic activities in less dense areas outside urban centers $[3,4,12,15,43,44,46,47]$. More specifically, two processes contributed to long-term demographic dynamics in this region: urban sprawl in the main metropolitan areas and 'coastalization' along the Mediterranean shoreline. The latter phenomenon has been extensively studied in the Mediterranean context, e.g. in Spain, where the coastline has become a favorite destination for tourism development and second-home urban expansion [69]. Tourism-specialized districts display accelerated demographic dynamics than urban areas in the respective country [70]. Moreover, several areas have been subject to informal buildings and deregulated planning, leading to spontaneous settlements or spatially-uncoordinated urban morphologies [5,49-51]. Finally, the most recent economic crisis had distinctive consequences and impacts on population distribution, especially in Greece, Italy, and Spain $[39,41,48]$. 
Socioeconomic transformations in Southern Europe are the result of multiple factors [56]. In recent decades, urbanization and demographic dynamics have played a key role in shaping the spatial distribution of resident population: areas close to major cities were experiencing a more dispersed urban expansion, possibly reflecting a high consumption of rural and marginal land [12,57]. However, results of this study document distinctive, within-countries urban processes. Location factors promote the development of economic activities and related services, especially in the 1960s and the 1970s, resulting in demographic expansion in local contexts with high population density [22,60]. Population growth was substantially unaffected by density levels in the subsequent decades, highlighting a prolonged wave of suburbanization especially in Spain, Greece, and Italy, in line with the empirical results of earlier studies. Re-urbanization processes were reflected in a positive relationship between population growth and density over the last decade of study.

Recent urbanization processes in Mediterranean regions have played a critical role in Europe [10,71], creating urban and rural poles and promoting disparities along elevation gradients. In this regard, territorial disparities exerted an important impact on Mediterranean landscapes-which have recently become more fragmented thanks to discontinuous urbanization $[12,18,24,25,62,67,72-78]$. This phenomenon caused more volatile demographic dynamics, new land-use structures, uneven changes in local housing markets, and social segregation [4,11,20,42,59,67,79]. A comparative analysis of local-scale population dynamics emphasizes the inherent complexity of different European contexts and the importance of a diachronic investigation of demographic phenomena [3,4,7-10,12-14,18,24,55,60]. Interregional disparities also reflect the inherent capacity to attract capital and infrastructures and to promote local development [8]. These factors are more intense in demographically-dynamic regions, such as northeastern Spain and northern Italy [55]. The diversity among countries also derives from their history, traditions and consistency of spatial management tools and practices [2]. Spatial planning has influenced urban trends across different European regions, from the Western planning tradition to new planning systems in Northern and Eastern Europe [12,47]. Spatial planning in the Mediterranean basin was relatively weak and decisions on land-use were sometimes poorly participated, leading to uncontrolled proliferation of settlements around central cities at least since the late 1980s [5,49]. A progressive transformation of rural areas into mixed peri-urban landscapes was stimulated by unregulated planning, inadequate zoning tools and a lack of controls, which has sometimes led to informal settlements [5,13,14,16,25,41,43,44,61-64,80].

\section{Conclusions}

The present study finally outlines the inherent difficulty of a theoretically-informed population growth analysis because of multiple, non-linear forces shaping natural balance and migratory movements in a distinctive way at different spatial and temporal scales. However, a coherent analysis of demographic trends comparing several countries in Southern Europe, may clarify the role of local contexts when implementing national policies or designing joint strategies for spatial planning and regional development at the European scale [81,82]. Based on population dynamics, territorial disparities can be more easily identified at the LAU scale, being primarily associated with urban sprawl and coastalization processes, both intensifying the socioeconomic divide in urban, accessible and dynamic regions and marginal, inland, and rural districts. Refined definitions of socioeconomic contexts resulting from different demographic patterns and processes can improve the reliability and accuracy of land-use analysis and predictions [50,83-87]. Although evaluation of spatial planning and developmental policies is not immediate [88], geo-spatial databases covering enough long study periods are essential to provide the information required to identify European regions, urban structures, peri-urban landscapes, and socioeconomic contexts changing over time [20]. Results of a spatially-explicit analysis of population dynamics in Southern Europe definitely suggests a reframe of country-wide strategies and regional policies adapting to progressively more volatile and heterogeneous local contexts. 
Author Contributions: L.S. and R.K. conceived and designed the experiments; I.Z. and A.C. performed the experiments; I.Z. and L.S. analyzed the data; R.K. and P.S. contributed analysis tools; I.Z. and L.S. wrote the paper.

Funding: This work was supported by a grant of the Ministry of Education of Czech Republic, NPU I(LO1415).

Conflicts of Interest: The authors declare no conflict of interest.

\section{References}

1. Colantoni, A.; Zambon, I.; Gras, M.; Mosconi, E.M.; Stefanoni, A.; Salvati, L. Clustering or Scattering? The Spatial Distribution of Cropland in a Metropolitan Region, 1960-2010. Sustainability 2018, 10, 1-12. [CrossRef]

2. Salvati, L.; Carlucci, M. Land-use structure, urban growth, and periurban landscape: A multivariate classification of the European cities. Environ. Plan. B Plan. Des. 2015, 42, 801-829. [CrossRef]

3. Oueslati, W.; Alvanides, S.; Garrod, G. Determinants of urban sprawl in European cities. Urban Stud. 2015, 52, 1594-1614. [CrossRef] [PubMed]

4. Salvati, L.; Carlucci, M. Patterns of sprawl: The socioeconomic and territorial profile of dispersed urban areas in Italy. Reg. Stud. 2016, 50, 1346-1359. [CrossRef]

5. Salvati, L.; Gargiulo Morelli, V. Unveiling urban sprawl in the Mediterranean region: Towards a latent urban transformation? Int. J. Urban and Reg. Res. 2014, 38, 1935-1953. [CrossRef]

6. Antunez, K.; Baccaïni, B.; Guérois, M.; Ysebaert, R. Disparities and territorial discontinuities in France with its new regions: A multiscalar and multidimensional interpretation. Écon. Stat. 2017, 497, 19-41. [CrossRef]

7. Bracalente, B.; Perugini, C. The components of regional disparities in Europe. Ann. Reg. Sci. 2010, 44, 621-645. [CrossRef]

8. Kasanko, M.; Barredo, J.I.; Lavalle, C.; McCormick, N.; Demicheli, L.; Sagris, V.; Brezger, A. Are European cities becoming dispersed? A comparative analysis of 15 European urban areas. Landsc. Urban Plan. 2006, 77, 111-130. [CrossRef]

9. Salvati, L.; Carlucci, M. Distance matters: Land consumption and the mono-centric model in two southern European cities. Landsc. Urban Plan. 2014, 127, 41-51. [CrossRef]

10. Salvati, L.; Carlucci, M. The economic and environmental performances of rural districts in Italy: Are competitiveness and sustainability compatible targets? Ecol. Econ. 2011, 70, 2446-2453. [CrossRef]

11. Salvati, L.; Zambon, I.; Chelli, F.M.; Serra, P. Do spatial patterns of urbanization and land consumption reflect different socioeconomic contexts in Europe? Sci. Total Environ. 2018, 625, 722-730. [CrossRef] [PubMed]

12. Zambon, I.; Serra, P.; Sauri, D.; Carlucci, M.; Salvati, L. Beyond the 'Mediterranean city': Socioeconomic disparities and urban sprawl in three Southern European cities. Geogr. Ann. Ser. B Hum. Geogr. 2017, 99, 319-337. [CrossRef]

13. Zitti, M.; Ferrara, C.; Perini, L.; Carlucci, M.; Salvati, L. Long-Term Urban Growth and Land Use Efficiency in Southern Europe: Implications for Sustainable Land Management. Sustainability 2015, 7, 3359-3385. [CrossRef]

14. Alphan, H. Land-use change and urbanization of Adana, Turkey. Land Degrad. Dev. 2003, 14, 575-586. [CrossRef]

15. Moos, M.; Mendez, P. Suburban ways of living and the geography of income: How homeownership, single-family dwellings and automobile use define the metropolitan social space. Urban Stud. 2015, 52, 1864-1882. [CrossRef]

16. Turok, I. Cities, regions and competitiveness. Reg. Stud. 2004, 38, 1061-1075. [CrossRef]

17. Zambon, I.; Ferrara, A.; Salvia, R.; Mosconi, E.M.; Fici, L.; Turco, R.; Salvati, L. Rural Districts between Urbanization and Land Abandonment: Undermining Long-Term Changes in Mediterranean Landscapes. Sustainability 2018, 10, 1159. [CrossRef]

18. Chéry, J.P. Les espaces périurbains en Europe: Un grand écart entre description et prospective. Revue d'études et de Prospective 2010, 2, 61.

19. Duvernoy, I.; Zambon, I.; Sateriano, A.; Salvati, L. Pictures from the Other Side of the Fringe: Urban Growth and Peri-urban Agriculture in a Post-industrial City (Toulouse, France). J. Rural Stud. 2018, 57, 25-35. [CrossRef]

20. Hudson, R. European integration and new forms of uneven development: But not the end of territorially distinctive capitalisms in Europe. Eur. Urban Reg. Stud. 2003, 10, 49-67. [CrossRef] 
21. Petrakos, G.; Rodríguez-Pose, A.; Rovolis, A. Growth, integration, and regional disparities in the European Union. Environ. Plan. A 2005, 37, 1837-1855. [CrossRef]

22. Biasi, R.; Colantoni, A.; Ferrara, C.; Ranalli, F.; Salvati, L. In-between Sprawl and Fires: Long-term Forest Expansion and Settlement Dynamics at the Wildland-Urban Interface in Rome, Italy. Int. J. Sustain. Dev. World Ecol. 2015, 22, 467-475. [CrossRef]

23. Salvati, L. Urban expansion and high-quality soil consumption-An inevitable spiral? Cities 2013, 31, 349-356. [CrossRef]

24. Salvati, L.; Gemmiti, R.; Perini, L. Land degradation in Mediterranean urban areas: An unexplored link with planning? Area 2012, 44, 317-325. [CrossRef]

25. Zambon, I.; Benedetti, A.; Ferrara, C.; Salvati, L. Soil Matters? A Multivariate Analysis of Socioeconomic Constraints to Urban Expansion in Mediterranean Europe. Ecol. Econ. 2018, 146, 173-183. [CrossRef]

26. Salvati, L. The 'Sprawl Divide': Comparing models of urban dispersion in mono-centric and polycentric Mediterranean cities. Eur. Urban Reg. Stud. 2016, 23, 338-354. [CrossRef]

27. Kazemzadeh-Zow, A.; Zanganeh Shahraki, S.; Salvati, L.; Neisani Samani, N. A Spatial Zoning Approach to Calibrate and Validate Urban Growth Models. Int. J. Geogr. Inf. Sci. 2017, 31, 763-782. [CrossRef]

28. Schneider, A.; Woodcock, C.E. Compact, dispersed, fragmented, extensive? A comparison of urban growth in twenty-five global cities using remotely sensed data, pattern metrics and census information. Urban Stud. 2008, 45, 659-692. [CrossRef]

29. Solon, J. Spatial context of urbanization: Landscape pattern and changes between 1950 and 1990 in the Warsaw metropolitan area, Poland. Landsc. Urban Plan. 2009, 93, 250-261. [CrossRef]

30. Bish, B.; Nourse, H. Urban Economics and Policy Analysis; Mc Graw-Hill Book Company: New York, NY, USA, 1975.

31. Haase, A.; Bernt, M.; Großmann, K.; Mykhnenko, V.; Rink, D. Varieties of shrinkage in European cities. Eur. Urban Reg. Stud. 2016, 23, 86-102. [CrossRef]

32. Paulsen, K. Geography, policy or market? New evidence on the measurement and causes of sprawl (and infill) in US metropolitan regions. Urban Stud. 2014, 51, 2629-2645. [CrossRef]

33. Bruegmann, R. Sprawl: A Compact History; University of Chicago Press: Chicago, IL, USA, 2005.

34. Haughton, G. Urban environmental management and welfare regimes: Some speculations. Eur. Urban Reg. Stud. 1999, 6, 275-280. [CrossRef]

35. Mykhnenko, V.; Turok, I. East European cities-Patterns of growth and decline, 1960-2005. Int. Plan. Stud. 2008, 13, 311-342. [CrossRef]

36. Petrakos, G.; Tsoukalas, D. The Impact of the Internationalization of the Structural Changes and of the Development on the Phenomenon of urban Polarization in Greece; Athens University of Economics: Athina, Greece, 1993.

37. Cecchini, M.; Zambon, I.; Pontrandolfi, A.; Turco, R.; Colantoni, A.; Mavrakis, A.; Salvati, L. Urban sprawl and the 'olive'landscape: Sustainable land management for 'crisis' cities. GeoJournal 2018, 1-19.

38. Méndez, R.; Sánchez-Moral, S.; Malfeito-Gaviro, J. Employment changes in knowledge-based industries in large urban areas of Spain: Impact of the economic crisis and austerity policies. Environ. Plan. C Gov. Policy 2016, 34, 963-980. [CrossRef]

39. Salvati, L.; Colantoni, A. Land use dynamics and soil quality in agro-forest systems: A country-scale assessment in Italy. J. Environ. Plan. Manag. 2015, 58, 175-188. [CrossRef]

40. Souliotis, N. Cultural economy, sovereign debt crisis and the importance of local contexts: The case of Athens. Cities 2013, 33, 61-68. [CrossRef]

41. Serra, P.; Vera, A.; Tulla, A.F.; Salvati, L. Beyond urban-rural dichotomy: Exploring socioeconomic and land-use processes of change in Spain (1991-2011). Appl. Geogr. 2014, 55, 71-81. [CrossRef]

42. Colantoni, A.; Grigoriadis, E.; Sateriano, A.; Venanzoni, G.; Salvati, L. Cities as selective land predators? A lesson on urban growth, deregulated planning and sprawl containment. Sci. Total Environ. 2016, 545, 329-339. [CrossRef]

43. Giannakourou, G. Transforming spatial planning policy in Mediterranean countries: Europeanization and domestic change. Eur. Plan. Stud. 2005, 13, 319-331. [CrossRef]

44. Ceccarelli, T.; Bajocco, S.; Perini, L.; Salvati, L. Urbanization and Land Take of High Quality Agricultural Soils-Exploring Long-term Land Use Changes and Land Capability in Northern Italy. Int. J. Environ. Res. 2014, 8, 181-192. 
45. Antrop, M. Landscape change and the urbanization process in Europe. Landsc. Urban Plan. 2004, 67, 9-26. [CrossRef]

46. Di Feliciantonio, C.; Salvati, L. 'Southern' Alternatives of Urban Diffusion: Investigating Settlement Characteristics and Socio-Economic Patterns in Three Mediterranean Regions. Tijdschrift Voor Economische en Sociale Geografie 2015, 106, 453-470. [CrossRef]

47. Crescenzi, R.; Luca, D.; Milio, S. The geography of the economic crisis in Europe: National macroeconomic conditions, regional structural factors and short-term economic performance. Camb. J. Reg. Econ. Soc. 2016, 9, 13-32. [CrossRef]

48. De Rosa, S.; Salvati, L. Beyond a 'side street story'? Naples from spontaneous centrality to entropic polycentricism, towards a 'crisis city'. Cities 2016, 51, 74-83. [CrossRef]

49. Pili, S.; Grigoriadis, E.; Carlucci, M.; Clemente, M.; Salvati, L. Towards Sustainable Growth? A Multi-criteria Assessment of (Changing) Urban Forms. Ecol. Indic. 2017, 76, 71-80. [CrossRef]

50. Salvati, L.; Carlucci, M. Urban growth, population, and recession: Unveiling multiple spatial patterns of demographic indicators in a Mediterranean City. Popul. Space Place 2017, 23, 8. [CrossRef]

51. Kiochos, P.; Rontos, K. Urbanization and Large Cities in the Mediterranean Countries. Arch. Econ. Hist. 1999, $10,1-2$.

52. United Nations. World Urbanization Prospects; The 1992 Revision; United Nations: New York, NY, USA, 1992.

53. Sidiropoulos, E. Economics of the Urban Centers; Lectures; Department of Public Administration, Panteion University: Kallithea, Greece, 1985.

54. Amendola, A.; Caroleo, F.E.; Coppola, G. Regional Disparities in Europe; The European Labour Market; Physica-Verlag: Heidelberg, Germany, 2006; pp. 9-31.

55. Lambin, E.F.; Meyfroidt, P. Land use transitions: Socioecological feedback versus socioeconomic change. Land Use Policy 2010, 27, 108-118. [CrossRef]

56. Clemente, M.; Zambon, I.; Konaxis, I.; Salvati, L. Urban growth, economic structures and demographic dynamics: Exploring the spatial mismatch between planned and actual land-use in a Mediterranean city. Int. Plan. Stud. 2018, 23, 376-390. [CrossRef]

57. European Environment Agency. Urban Sprawl in Europe-The Ignored Challenge; European Environmental Agency: Copenhagen, Denmark, 2006.

58. Colantoni, A.; Mavrakis, A.; Sorgi, T.; Salvati, L. Towards a 'polycentric' landscape? Reconnecting fragments into an integrated network of coastal forests in Rome. Rendiconti Accademia Nazionale dei Lincei 2015, 26, 615-624. [CrossRef]

59. Edervee, S.; Gorter, J. Does European Cohesion Policy Reduce Regional Disparities? CPB Netherlands Bureau for Economic Policy Analysis: The Hague, The Netherlands, 2002.

60. Carlucci, M.; Grigoriadis, E.; Rontos, K.; Salvati, L. Revisiting a Hegemonic Concept: Long-term 'Mediterranean Urbanization' in between city re-polarization and metropolitan decline. Appl. Spat. Anal. Policy 2017, 10, 347-362. [CrossRef]

61. Colantoni, A.; Ferrara, C.; Perini, L.; Salvati, L. Assessing Trends in Climate Aridity and Vulnerability to Soil Degradation in Italy. Ecol. Indic. 2015, 48, 599-604. [CrossRef]

62. Gospodini, A. Portraying, classifying and understanding the emerging landscapes in the post-industrial city. Cities 2006, 23, 311-330. [CrossRef]

63. Salvati, L.; Quatrini, V.; Barbati, A.; Tomao, A.; Mavrakis, A.; Serra, P.; Sabbi, A.; Merlini, P.; Corona, P. Soil occupation efficiency and landscape conservation in four Mediterranean urban regions. Urban For. Urban Green. 2016, 20, 419-427. [CrossRef]

64. Russo, A.P.; Serrano Giné, D.; Pérez Albert, M.Y.; Brandajs, F. Identifying and Classifying Small and Medium Sized Towns in Europe. Tijdschrift Voor Economische en Sociale Geografie 2017. [CrossRef]

65. Lauf, S.; Haase, D.; Kleinschmit, B. The effects of growth, shrinkage, population aging and preference shifts on urban development-A spatial scenario analysis of Berlin, Germany. Land Use Policy 2016, 52, $240-254$. [CrossRef]

66. Ferrara, A.; Salvati, L.; Sabbi, A.; Colantoni, A. Urbanization, Soil Quality and Rural Areas: Towards a Spatial Mismatch? Sci. Total Environ. 2014, 478, 116-122. [CrossRef]

67. Grekousis, G.; Manetos, P.; Photis, Y.N. Modeling urban evolution using neural networks, fuzzy logic and GIS: The case of the Athens metropolitan area. Cities 2013, 30, 193-203. [CrossRef] 
68. Catalán, B.; Saurí, D.; Serra, P. Urban sprawl in the Mediterranean? Patterns of growth and change in the Barcelona Metropolitan Region 1993-2000. Landsc. Urban Plan. 2008, 85, 174-184. [CrossRef]

69. Gavalas, V.S.; Rontos, K.; Salvati, L. Who becomes an unwed mother in Greece? Socio-demographic and geographical aspects of an emerging phenomenon. Popul. Space Place 2014, 20, 250-263. [CrossRef]

70. Tselios, V.; Rovolis, A.; Psycharis, Y. Regional Economic Development, Human Capital and Transport Infrastructure in Greece: The Role of Geography. In Regional Upgrading in Southern Europe; Springer: Cham, Switzerland, 2017.

71. Barbati, A.; Corona, P.; Salvati, L.; Gasparella, L. Natural forest expansion into suburban countryside: Gained ground for a green infrastructure? Urban For. Urban Green. 2013, 12, 36-43. [CrossRef]

72. Delfanti, L.; Colantoni, A.; Recanatesi, F.; Bencardino, M.; Sateriano, A.; Salvati, L. Solar plants, environmental degradation and local socioeconomic contexts: A case study in a Mediterranean country. Environ. Assess. Impact Rev. 2016, 61, 88-93. [CrossRef]

73. Salvati, L.; Zitti, M.; Ceccarelli, T. Integrating economic and environmental indicators in the assessment of desertification risk: A case study. Appl. Ecol. Environ. Res. 2008, 6, 129-138. [CrossRef]

74. Salvati, L.; Bajocco, S.; Ceccarelli, T.; Zitti, M.; Perini, L. Towards a proces-based evaluation of soil vulnerability to degradation: A spatio-temporal approach in Italy. Ecol. Indic. 2011, 11, 1216-1227. [CrossRef]

75. Salvati, L.; Tombolini, I.; Gemmiti, R.; Carlucci, M.; Bajocco, S.; Perini, L.; Colantoni, A. Complexity in action: Untangling latent relationships between land quality, economic structures and socio-spatial patterns in Italy. PLoS ONE 2017, 12, e0177853. [CrossRef] [PubMed]

76. Munafò, M.; Salvati, L.; Zitti, M. Estimating soil sealing at country scale-Italy as a case study. Ecol. Indic. 2013, 26, 36-43. [CrossRef]

77. Cuadrado-Ciuraneta, S.; Durà-Guimerà, A.; Salvati, L. Not only tourism: Unravelling suburbanization, second-home expansion and "rural" sprawl in Catalonia, Spain. Urban Geogr. 2017, 38, 66-89. [CrossRef]

78. Colantoni, A.; Grigoriadis, E.; Sateriano, A.; Sarantakou, E.; Salvati, L. Back to Von Thunen: A Southern European perspective on mono-centric urban growth, economic structure and non-urban land decline. Int. Plan. Stud. 2017, 22, 173-188. [CrossRef]

79. Venanzoni, G.; Carlucci, M.; Salvati, L. Latent sprawl patterns and the spatial distribution of businesses in a southern European city. Cities 2017, 62, 50-61. [CrossRef]

80. RodrÍguez-Pose, A.; Fratesi, U. Between development and social policies: The impact of European Structural Funds in Objective 1 regions. Reg. Stud. 2004, 38, 97-113. [CrossRef]

81. Weilenmann, B.; Seidl, I.; Schulz, T. The socioeconomic determinants of urban sprawl between 1980 and 2010 in Switzerland. Landsc. Urban Plan. 2017, 157, 468-482. [CrossRef]

82. Cerdà, A.; Rodrigo-Comino, J.; Giménez-Morera, A.; Keesstra, S.D. An economic, perception and biophysical approach to the use of oat straw as mulch in Mediterranean rainfed agriculture land. Ecol. Eng. 2017, 108, 162-171. [CrossRef]

83. Parras-Alcántara, L.; Lozano-García, B.; Keesstra, S.; Cerdà, A.; Brevik, E.C. Long-term effects of soil management on ecosystem services and soil loss estimation in olive grove top soils. Sci. Total Environ. 2016, 571, 498-506. [CrossRef] [PubMed]

84. Pereira, P.; Brevik, E.C.; Muñoz-Rojas, M.; Miller, B.A.; Smetanova, A.; Depellegrin, D.; Cerdà, A. Soil Mapping and Processes Modeling for Sustainable Land Management. In Soil Mapping and Process Modeling for Sustainable Land Use Management; Elsevier: Amsterdam, The Netherlands, 2017; pp. 29-60.

85. Rodrigo-Comino, J.; Martínez-Hernández, C.; Iserloh, T.; Cerdà, A. The contrasted impact of land abandonment on soil erosion in Mediterranean agriculture fields. Pedosphere 2018, 28, 617-631. [CrossRef]

86. Van Der Burg, A.J.; Dieleman, F.M. Dutch urbanization policies: From 'compact city'to 'urban network'. Tijdschrift Voor Economische en Sociale Geografie 2004, 95, 108-116. [CrossRef]

87. Salvati, L. Agro-forest landscape and the 'fringe'city: A multivariate assessment of land-use changes in a sprawling region and implications for planning. Sci. Total Environ. 2014, 490, 715-723. [CrossRef]

88. Morelli, V.G.; Rontos, K.; Salvati, L. Between suburbanisation and re-urbanisation: Revisiting the urban life cycle in a Mediterranean compact city. Urban Res. Pract. 2014, 7, 74-88. [CrossRef]

(C) 2018 by the authors. Licensee MDPI, Basel, Switzerland. This article is an open access article distributed under the terms and conditions of the Creative Commons Attribution (CC BY) license (http:/ / creativecommons.org/licenses/by/4.0/). 